\section{TURISMO INDÍGENA COMO RESPUESTA A LA SINIESTRALIDAD: COMUNIDAD MAPUCHE-LAFKENCHE DEL LAGO BUDI, CHILE}

Ricardo Alvarez $^{1, *}$, Fernanda Azócar ${ }^{2}$, Gabriela Marihuan ${ }^{3}$, Aldo Montero ${ }^{4}$ y Mauricio Rosenbluth ${ }^{5}$

\section{RESUMEN}

Durante casi 20 años la comunidad Mapuche-lafkenche de Llaguepulli, que habita en la ribera sur del Lago Budi en la región de La Araucanía, Chile, ha impulsado una estrategia de desarrollo local excepcional, que surge como respuesta a la profunda crisis económica, social y cultural que experimentaron en la década de los ' 80 y ' 90 . Dicha crisis fue el desenlace de un largo proceso de segregación, reducción territorial y aislamiento al cual fue sometida ésta comunidad. La estrategia desplegada por ellos se halla sostenida en un variado y complejo portafolio de recursos endógenos de carácter humano, social, cultural y natural que durante mucho tiempo permaneció invisible, inactivo o devaluado por la sociedad chilena. Esta historia partió con un objetivo muy práctico e inmediato para la gente de Llaguepulli: buscar alternativas laborales generadoras de ingresos, sin tener que dejar el territorio. Esta búsqueda los llevó a dibujar un nuevo horizonte de lo posible, escalando hacia un marco económico local, que combinó sus actividades productivas tradicionales con el inicio de un negocio turístico de intereses especiales, de carácter rural-cultural y códigos solidarios de conducta, que al día de hoy ha robustecido significativamente el control y dominio de la comunidad sobre su propio territorio y destino.

\section{PALABRAS CLAVE}

Crisis, Siniestro, Lago Budi, Mapuche-lafkenche, Lewfu Budi

\section{INDIGENOUS TOURISM AS A RESPONSE TO CRISIS: MAPUCHE-LAFKENCHE COMMUNITY OF BUDI LAKE, CHILE}

\section{ABSTRACT}

For almost 20 years, the Mapuche-lafkenche community of Llaguepulli in the south bank of Budi lake in the La Araucanía region, Chile, has promoted an exceptional local development strategy. This arose in response to the deep economic, social and cultural crisis that they experienced in the decade of the ' 80 s and' 90 s. The crisis was the outcome of a long process of segregation, territorial reduction and isolation experienced by this community. Their strategy to recover from this crisis sustained in a varied and complex portfolio of endogenous human, social, cultural and natural resources that for a long time remained invisible, inactive or devalued by Chilean society. This story started with a very practical objective for the people of Llaguepulli: to look for income-generating job alternatives, but without having to leave its territory. This search led them to draw a new horizon of what was possible, scaling towards a local economic framework, which combined their traditional productive activities with the start of a tourism business with special interests, ruralcultural character and solidarity codes of conduct. Years later, the community has significantly strengthened its own organization and gained control over its territory.

\section{KEYWORDS}

Crisis, Threatening, Budi lake, Mapuche-lafkenche, Lewfu Budi
1. Propuestas País - Zona Austral, Fundación Nacional para la Superación de la Pobreza, Puerto Montt, Chile.

2. Propuestas País -

Macrozona Centro,

Fundación Nacional para la Superación de la Pobreza, Rancagua, Chile.

3. Dirección Regional La Araucanía, Fundación Nacional para la Superación de la Pobreza, Temuco, Chile.

4. Consultor independiente, Santiago, Chile.

5. Propuestas País Dirección Nacional, Fundación Nacional para la Superación de la Pobreza, Santiago, Chile.

*Autor de correspondencia: ricardo.alvarez@ superacionpobreza.cl

\section{RECIBIDO}

20 de septiembre de 2018

\section{ACEPTADO}

28 de noviembre de 2018

\section{PUBLICADO}

1 de enero de 2019

\section{Formato cita}

Recomendada (APA): Alvarez, R., Azócar, F., Marihuan, G., Montero, A. y Rosenbluth, M. (2019). Turismo indígena como respuesta a la siniestralidad: Comunidad MapucheLafkenche del lago Budi, Chile, Revista de Estudios Latinoamericanos sobre Reducción del Riesgo de Desastres REDER, 3(1), pp.24-40.

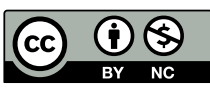

Todos los artículos publicados en REDER siguen una política de Acceso Abierto y se respaldan en una Licencia CreativeCommons Atribución-NoComercial 4.0 Internacional.

\section{Revista de Estudios}

Latinoamericanos sobre Reducción del Riesgo de Desastres (REDER)

Diseño: Lupe Bezzina Tipografía: Hospital 


\section{INTRODUCCIÓN: LA CRISIS DEL LAGO BUDI}

Desde los ochenta, y con más fuerza durante los noventa, las comunidades Mapuche-lafkenche del lago Budi exhibían una situación socioeconómica, cultural y ambiental muy compleja. Los indicadores oficiales mostraban que esta zona oscilaba entre el estancamiento y el empobrecimiento de su población: entre el 30 y $40 \%$ de sus habitantes estaban en situación de pobreza y la comuna presentaba unos de los índices de Desarrollo Humano más bajos del país: 0,526 (PNUD, 1996). Se trata de una crisis sistémica que amenazaba integralmente su modo de vida Mapuche-lafkenche en la zona.

A nivel económico, la manifestación más clara de esta crisis era la severidad de las carencias a nivel material y de ingresos. A diferencia de otras comunidades indígenas de la región, los asentamientos ribereños del Budi no contaban con servicios básicos, conectividad, información y servicios sociales, mismos que ya se habían vuelto habituales en otras zonas de la región. Escaseaba el trabajo, o éste generaba muy bajos ingresos. Las actividades productivas tradicionales -recolección de orilla, agrícola y ganadera principalmente- y la sobrepasada y desgastada capacidad ecológica del territorio, hacían muy difícil sostener siquiera una economía de subsistencia y generar ingresos por sobre la línea de la pobreza de la época.

A nivel social, la zona había sido golpeada por un extenso proceso de despoblamiento. En ese marco, se tornó prácticamente imposible desplegar una estrategia de vida para sus habitantes que pudiera responder a parámetros de desarrollo y progreso. La economía local se hizo incapaz de retener a la población, en especial, a la gente joven. La geografía humana del territorio se encontró envejecida, lo que dificultó aún más la autoproducción de los medios de vida en la zona.

El circuito de empobrecimiento encontró su 'broche de oro' en la crisis cultural. En efecto, el pueblo Mapuche-lafkenche había experimentado un larguísimo proceso de devaluación cultural, producto de la discriminación y el menosprecio de la sociedad chilena a su cultura, tradiciones y prácticas ancestrales. En ese entonces, muchas personas sentían vergüenza de ser mapuche lo que provocó un debilitamiento sistemático de la identidad y el apego territorial. En su reemplazo, surgieron conductas ambivalentes: la negación de la identidad, la desconfianza, la renuencia a encuentros colectivos, las dificultades para desarrollar acciones colectivas, entre otras cosas, daban cuenta de un ejercicio de protección ante una región y un país que se constituían como una amenaza de larga data.

Lo anterior, quedó parcialmente demostrado en el decreto que crea el ADI-BUDI':

"Considerando: Que en el sector del Lago Budi, existen hoy 37 comunidades indígenas, siendo éste su territorio ancestral, cuyos antecedentes históricos se remontan a la época prehispánica, lo que se respalda por sitios arqueológicos que testimonian la antigua data del poblamiento indígena. Que, el sector presenta una alta densidad indígena, con una población que alcanza a las 6.245 personas, radicadas en las comunidades [...] Que, los integrantes de dichas comunidades viven en condiciones de extrema pobreza, lo cual se expresa en insuficiencia de ingresos, deficiencias alimenticias, precarias condiciones de vivienda y deficientes indicadores de salud, que requieren para su superación de una coordinación efectiva de los programas que el Estado desarrollen en la zona [...] Que, por lo anteriormente señalado resulta indispensable establecer en la Cuenca del Lago Budi un área de desarrollo indígena, en cuyo espacio territorial los Organismos de la Administración focalicen su acción en beneficio del desarrollo armónico de la población indígena mapuche que la habita, así como la adopción de planes, proyectos y obras en tal sentido".

(Decreto Supremo N071 de MIDEPLAN, 10/03/1997)

En efecto, el ADI BUDI nace con el propósito de abordar las inequidades sociales, económicas, culturales y territoriales que afectan a las comunidades Mapuche-lafkenche de la zona, pero sin una adecuación a los instrumentos que comúnmente el Estado implementaba en áreas rurales no indígenas.

\section{EL ORIGEN DE LA CRISIS}

La historia de segregación de las comunidades mapuche hacia zonas en las que se aglutinaron, bajo una modalidad de hacinamiento y extrema pobreza histórica, fue el resultado de políticas

1. Área de Desarrollo Índígena Lago Budi 
públicas impulsadas durante la segunda mitad del siglo XIX por el Estado de Chile, bajo el paradójico término de 'pacificación de La Araucanía' (Bengoa, 2000; 2017). La finalidad de ello fue capturar y facilitar la explotación de los recursos naturales que yacían dentro de esta frontera indígena. Los territorios hacia los cuales fueron erradicadas las comunidades supervivientes eran, en general, 'improductivos' para la nación, y en ellos debieron aglomerarse cientos de familias que antes contaban con vastos espacios para experimentar sus estrategias económicas. No es menor considerar que hoy en día esta región posee los índices más altos de pobreza multidimensional (28,5\%) a nivel nacional (Casen, 2017).

Uno de estos afectados históricamente fue Lago Budi ( $38^{\circ} 53^{\prime} 00^{\prime \prime S}$ y $\left.73^{\circ} 17^{\prime} 00^{\prime \prime} \mathrm{O}\right)$, en la región de La Araucanía (Figura 1), cuerpo de agua salada que posee las mayores dimensiones a escala continental con respecto a su naturaleza. Sus costas están pobladas por comunidades indígenas Mapuche-lafkenche, que se distribuyen de forma dispersa por los lomajes y costas del lugar, aplicando una economía de subsistencia con énfasis en la agricultura y ganadería menor, tal como se aprecia en la Figura 2

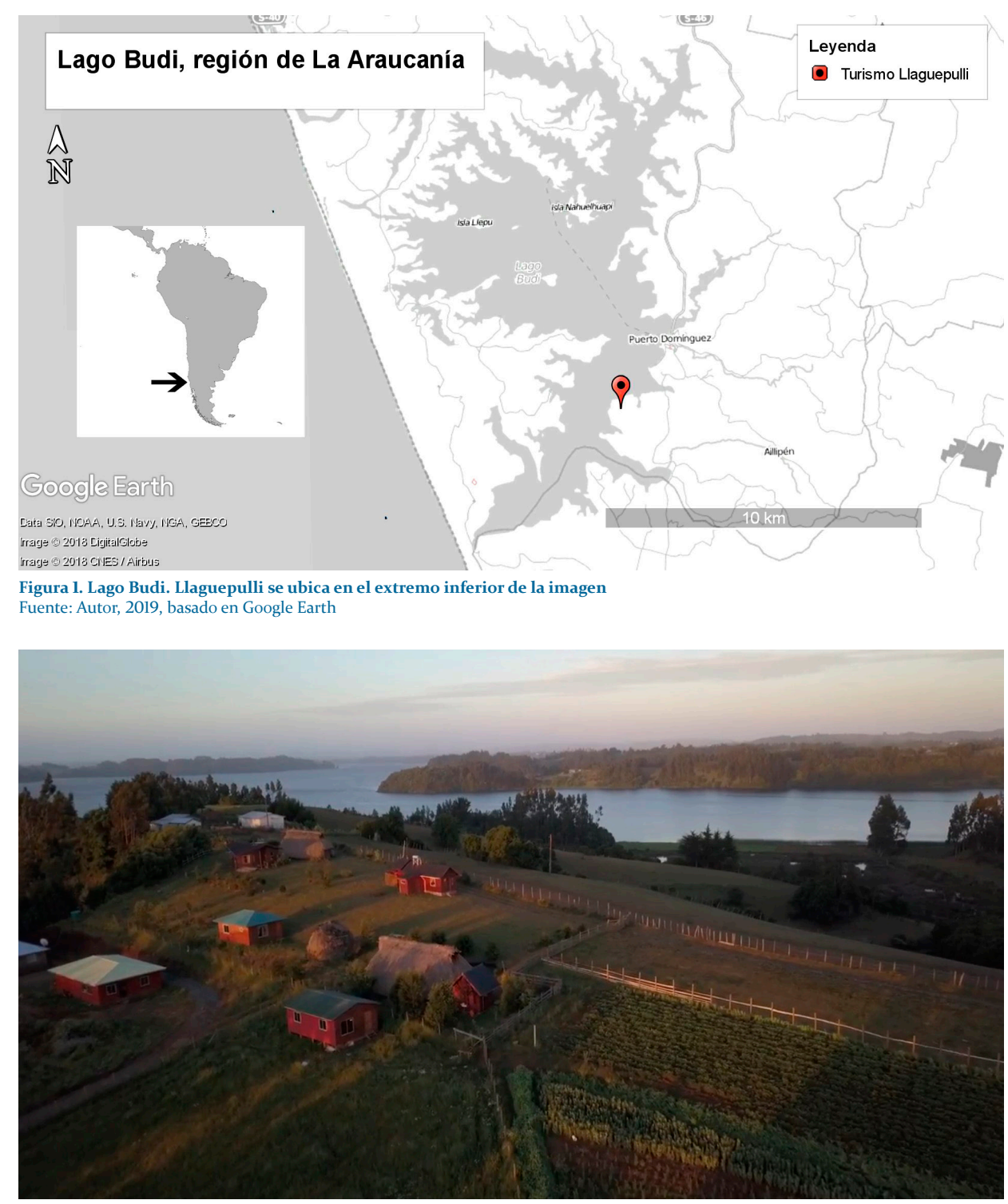

Figura 2. Zona de Llaguepulli, con rukas turísticas junto a los espacios habitacionales familiares Fuente: Documental Küme mogen lewfü Budi (Larraín, 2017).

Esta micro-parcelación forzada implicó un acelerado proceso de precarización y la inmovilización de sus satisfactores habituales sin posibilidad alguna de poder revertir este siniestro. Por el contrario, muy pronto las familias aglomeradas en esta zona se vieron enfrentadas a tener que tensionar sus habilidades y prácticas de vida para poder cohabitar sin entrar en conflicto entre sí. 
La presión a la que se vieron sometidas estas poblaciones generó un acelerado proceso de estancamiento en su modo de vida, pues impidió que pudiesen movilizar sus recursos más indispensables: les fue imposible, por ejemplo, sostener su economía tradicional en espacios tan reducidos, en los que ni siquiera la horticultura y ganadería menor permitían el sostenimiento familiar y colectivo. Para solucionar paliativamente esta situación recurrieron al pastoreo libre (ejercicio que ya conocían previamente) por los terrenos costeros, fenómeno que rápidamente se vio coartado tras la parcelación forzada que impuso el Estado para 'ordenar' estas reducciones: "[...] se tomó una regla y se fue trazando y dividiendo la propiedad por encima de todo lo que existía. Se desconoció toda la estructura social y la división territorial que tenían los mapuche" -Fernando Díaz, ex-párroco de Puerto Domínguez. Documental Küme mogen lewfü Budi (Larraín, 2017).

Por otro lado, los activos relacionales (asociados al trabajo, lo festivo y lo cosmogónico), fundamentales en la cultura Mapuche-lafkenche, no pudieron ser desplegados en un contexto de tensión de esta magnitud. Por el contrario, se activaron pseudo-satisfactores (Max-Neef Elizalde \& Hopenhayn, 1993) como la desconfianza hacia otros y la renuencia a generar encuentros grupales, agudizando su condición de vulnerabilidad la cual se potencia con la presión de una sociedad regional y nacional que actuaba amenazantemente sobre ellos, y que se había apropiado de los mejores terrenos para implementar proyectos de desarrollo agropecuario, subvencionados por el Estado. De esta forma el lago Budi inició una historia de invisibilización y precarización:

"Eso produjo un quiebre total, que [...] permanece hasta el día de hoy. Eso es lo que le cuesta a veces entender al mundo no indígena: que la ocupación de La Araucanía por el ejército, y después por los colonos y por las empresas colonizadoras, produjo una injusticia que permanece, es permanente, es constante, porque de una sociedad de la abundancia, como la mapuche -que no le faltaba nada, tenían de todo- pasó de la noche a la mañana, en pocos años, a colapsar, porque el ejército se llevó los animales, quemó las rucas, quemó las siembras, y trajo colonos y les quitó las tierras. Pasaron a vivir en la miseria total, reducidos. Significaba que donde había cinco o diez familias en 500, 900 o 1500 hectáreas, pasaron a vivir en 100 hectáreas, amontonados".

Ex-párroco de Puerto Domínguez. Documental Küme mogen lewfü Budi, (Larraín, 2017)

Durante ese período nacieron dos arquetipos en el territorio: por un lado las familias colonizadoras -chilenas y europeas- que adquirieron una connotación positiva, muy adheridos a una simbología patriótica y de un proyecto nacional de desarrollo. Por lo mismo, algunos de ellos recibieron importantes subvenciones para posicionarse territorialmente -principalmente quienes provenían de Europa. Mientras el peonaje chileno sirvió como mano de obra, habitando en torno a los primeros. Por otro, estaban las familias de origen indígena quienes fueron estigmatizadas como indolentes, rebeldes e improductivas (Casanueva, 2002; Herrera, 2003), y por lo mismo, una amenaza al proyecto de desarrollo en sí. De esta forma se estableció una frontera interior, "[...] lugar donde el Estado tiene débil presencia." (Toledo, 2001, p.159) que los separó física y simbólicamente de lo que estaba sucediendo en el país. Este prejuicio sigue estando muy vigente en este nuevo milenio (Cayuqueo, 2012a), y se podría decir que incluso se ha acrecentado cuando, por ejemplo, a esta pobreza histórica se le acusa de ser causal del deterioro medioambiental y rezago regional, aunque las evidencias demuestren lo contrario (Montalva et al., 2011; Cayuqueo, 2012b; FSP, 2016), y también como una amenaza nacional para los avances que ha logrado la industria forestal y grandes latifundistas.

Adicionalmente, durante el siglo XX las comunidades Mapuche-lafkenches de la zona, se vieron expuestas a importantes amenazas, como las sequías de 1920 y 1960 (Espíldora, 1972), el terremoto de 1960 y el tizón de la papa en el mismo período. El terremoto fue especialmente traumático para la zona de Budi pues vino acompañado por un maremoto que bloqueó desde entonces el drenaje natural de este lago salobre. Lo anterior provocó que, hasta el día de hoy, cada invierno las aguas inunden praderas de pastoreo y zonas de siembra. El terremoto generó un impacto tal en la población local que implicó la reactivación puntual de una práctica extrema y en desuso por largo tiempo: el sacrificio ritual de un niño, el que fue entregado a las olas con el propósito de que éstas regresasen con su destrucción hacia mar adentro (Montecino, 2011), lo que detonó nuevos prejuicios extremadamente negativos desde la sociedad nacional hacia estas comunidades, reforzando el arquetipo de que no merecían ser parte del país. 
Como se señaló previamente, fue recién a fines del siglo XX, y comienzos de este nuevo milenio, que el Estado comenzó a modificar el trato que durante tanto tiempo le dio a los Pueblos originarios, ensayando un rol comparativamente más benévolo, tratando de indemnizar el daño, vulneración y vulnerabilidad producida hacia estas miles de familias².

\section{LA RESPUESTA DEL ESTADO FRENTE A LA CRISIS: LA SINIESTRALIDAD PROVOCADA POR LAS DECISIONES PÚBLICAS}

El día 10 de marzo de 1997, mediante el Decreto Supremo N71 de MIDEPLAN, el Estado de Chile creó el Área de Desarrollo Indígena del Budi o ADI-Budi, la segunda en ser oficiada en el país. Según la Ley indígena 19.253, de 1993, el Estado "podrá establecer Áreas de Desarrollo Indígena que serán espacios territoriales en que los organismos de la administración pública del Estado focalizarán sus acciones en beneficio del desarrollo armónico de los indígenas y sus comunidades" (art.26) ${ }^{3}$.

Como se señaló previamente, la pobreza en la zona de lago Budi se había vuelto crónica, y era necesario hacerse cargo de ella. Para lograrlo se crearon servicios públicos asociados a emprendimientos, devoluciones de tierras, inversión en equipamiento y formación técnica, todas éstas focalizadas específicamente hacia personas y organizaciones de pueblos originarios. El problema es que estas políticas, esencialmente asistenciales, operaban bajo una lógica estándar a nivel nacional, que privilegiaban la competitividad entre pares y la resolución individual de los problemas, los que debían ser explicitados ante las autoridades como carencias. De esta forma surge la imagen de un 'beneficiario' pasivo, receptor de beneficios sociales. Además, el Estado fue enfático en señalar que los modos de vida locales debían ser reemplazados por el modelo de vida nacional, pues precisamente en ello radicaba su rezago:

"Es un momento de intervención desde todos lados y lo que hacen continuamente es decirles -'No, ustedes están mal'-, como diciendo -'Ustedes son los ignorantes y tienen que aprender lo que nosotros les venimos a enseñar'-. Viene el INDAP y les dice -'No, esta forma de sembrar con bueyes las papas, hay que poner abonos, insecticidas, pesticidas'. Viene el SERVIU -'No, que estas rucas son insalubres'- [...] En la escuela les decían -'Hay cabrito, tienen que estudiar y aprender castellano, o si no le van a andar picando el poto a los bueyes igual que sus papás'-[...] así, textual, desvalorización de la familia. Y hay dos posibilidades: irte de la tierra, y la gente migra, una inmensa migración: el $80 \%$ de la población mapuche vive fuera de sus comunidades en sectores urbanos, trabajando en los últimos escalones sociales. Y los que van quedando en los campos son los niños y los viejos, y muy pocos jóvenes, porque la migración era muy alta en esa época".

\section{Ex-párroco de Puerto Domínguez. Documental Küme mogen lewfü Budi (Larraín, 2017)}

Estas políticas de intervención centradas en un desarrollo exógeno y sin consideraciones territoriales, contravenían parte importante de los arreglos culturales de estas comunidades, las que -a pesar de haber estado seriamente impactada- seguía siendo clave en la construcción identitaria y el arraigo en este nuevo territorio, que ya habían hecho propio, organizándolo en base al Lof -esto es, comunidades basadas en linajes familiares, que poseen un Longko como líder y fronteras más bien simbólicas.

Es por ello que poco a poco algunas organizaciones indígenas, en el sur del país, que sufrían los mismos problemas, comenzaron a visualizar algunos elementos de la estructura de oportunidades (Kaztman \& Filgueira, 1999) no indígena, principalmente pública (Estado) para adecuarla a sus propias necesidades y territorios, en un escenario en el que el acceso a ésta estaba básicamente limitado a programas de asistencia estatal que se aplicaban de forma vertical (top down) sin aviso previo. En este sentido, es necesario considerar que la propia estructura de oportunidades Mapuche-lafkenche de este lago estaba constituida principalmente por lazos de parentesco, respeto y afiliación a un lof, así como a procedimientos y actividades comunitarias, pero que sólo eran eficaces dentro de este espacio. Fuera de éste se debilitaban pues no eran válidos para la sociedad chilena y su entramado político-administrativo, cultural, entre otros. A escala macroterritorial, este ejercicio colectivo de experimentación con las reglas del otro -dio fruto, por ejemplo, con el surgimiento de algunas organizaciones territoriales, como Pu Lafkenche, Newén Pu Lafkenche e Identidad Lafkenche, y logros como la Ley 20.249, llamada también Ley lafkenche (Foerster \& Lavanchy, 1999; Castro, 2005; Flores, 2009; Zelada \& Park, 2013; Gissi et al., 2018). Estos
2. Con ello enfatizamos el hecho de que tanto el riesgo como la vulnerabilidad son producciones, en un escenario en el que las amenazas siempre están presentes.

3. Los criterios de Conformación de Ârea de Desarrollo Indígena son: a) Espacios territoriales en que han vivido ancestralmente etnias indígenas, b) Alta densidad de población indígena, c) Existencia de comunidades o individuos indígenas, d) Homogeneidad ecológica y, e) Dependencia de recursos naturales para el equilibrio de estos territorios, tales cuencas, ríos, riveras, flora y fauna. 
logros tienen como precedente procesos político-territoriales previos, como el Consejo de Todas las Tierras (Neira, 2009), intercambios con otros pueblos originarios de América Latina, y el acompañamiento de ONG's como Ayuda Popular Noruega, Fundación Impulsa y Fundación Superación Pobreza, los que permitieron romper con algunas de las barreras para que estas comunidades se arriesgaran a romper los pasivos de seguridad.

En este marco, a comienzos de los 2000, surge la iniciativa turística 'Naturaleza y Cultura ancestral en el Budi' en la comunidad de Llaguepulli. Esta experiencia se basó en la producción de micro-negocios turísticos indígenas y con enfoque comunitario, a orillas del Lago Budi (Carvallo et al., 2018; Escalona, 2012; Cifuentes \& Garrido, 2017; Montero, 2014). Este es el caso que se quiere desarrollar en este artículo, pues se advierte a un conjunto de micro-organizaciones, con una biografía muy devaluada y violentada, y que experimentaban una crisis sistémica de pasivos y satisfactores, pero que lograron sortear la crisis sistémica del Budi y el re-siniestro que implicó el primer gran ejercicio de focalización territorial tras la declaratoria de ADI. Si bien se trata de un caso muy lugarizado, los recursos desplegados por estas familias deben ser valorados pues, en la práctica, lo que se advierte es la recomposición de un tejido social y cultural que habita una zona caracterizada históricamente por siniestros normativos, político-administrativos y ambientales, y que por la fortaleza que está adquiriendo actúa como una potente herramienta ante la gestión del riesgo de desastres.

\section{MARCO METODOLÓGICO Y EPISTEMOLÓGICO}

El presente artículo se enmarca en el programa Levantamiento de Aprendizajes que la Fundación para la Superación de la Pobreza realiza cada año sobre sus intervenciones asociadas al programa Servicio País, donde se exhiben distintos procesos virtuosos de transformación social. En este sentido, el objetivo de este Levantamiento de Aprendizajes fue reconstruir el proceso de transformación de la agrupación Lewfu Budi, a nivel objetivo, subjetivo y relacional. Para dicho objetivo, la recolección de datos consistió, fundamentalmente, en fuentes primarias de corte cualitativo, que nos permitieron profundizar y analizar la discusión colectiva sobre aspectos subjetivos y de sentido (Taylor \& Bogdan, 1982) de la comunidad Lafkenche. Esta información primaria fue levantada en diferentes períodos de tiempo: i) en el año 2014 como parte de la implementación del propio ejercicio de Levantamiento de Aprendizajes (Montero, 2014), que recogió relatos de los habitantes y de los ex profesionales ligados al ciclo de intervención (1998-2001) a través de entrevistas semi estructuradas y grupales. El año 2015, como parte de la celebración de los 20 años del programa Servicio País, lo que incluyó reconstruir experiencias significativas utilizando las mismas técnicas; y el año 2017 a partir de la creación del documental Küme mogen lewfü Budi (Larraín, 2017), en cuyo proceso de realización volvieron a entrevistarse a personas, actores clave y ex profesionales que formaron parte de dicha historia, esta vez utilizando registro audiovisual tanto de los actores como de las locaciones manifestadas en sus relatos. También se recurrió a numerosos artículos, estudios e informes, que dan cuenta de la complejidad y riqueza de esta experiencia (Castro, 2005; Escalona et al., 2012; RIMISP, 2013; Cadierno, 2016; Cifuentes \& Garrido, 2017; Carvallo et al., 2018).

Los análisis fueron realizados en base a tres enfoques: i) Enfoque Activos, Vulnerabilidades y Estructura de Oportunidades de Ruben Kaztman y Filgueira (1999), que permite indagar cómo se construye el proceso de transformación de la comunidad, relevando sus distintos recursos, activos y pasivos, a la vez de actores y barreras del entorno, poniendo en el centro al sujeto colectivo de las intervenciones sociales; ii) Enfoque de Necesidades de Manfred Max-Neef et al. (1993), que nutre el análisis a partir de las necesidades y satisfactores que se generan y utilizan ante los distintos siniestros las comunidades Lafkenches; y iii) Modelo de Liberación y Presión de Blaike (1996), que permite analizar cuáles han sido las presiones de orden normativo que han degradado el territorio y las comunidades, generando pasivos, y cuales han sido las estrategias de liberación de éstos, transformándose como herramientas para la reducción de riesgo de desastres.

\section{LOS SINIESTROS INVISIBLES: LOS SINIESTROS NORMADOS}

Es frecuente que los siniestros ambientales (deslizamientos de laderas, tsunamis, terremotos, etc.) sean protagónicos en los relatos y estrategias de gestión del riesgo de desastres. Los afectados y víctimas son quienes experimentan y absorben directamente estos eventos en sus vidas familiares (Cutter et al., 2003), y los Estados asumen el costo económico que ello implica (UNIRSD, 2015). La prevención del riesgo surge como una estrategia para evitar que la población y los Estados deban pasar nuevamente por experiencias similares, lo que significa el reacomodo de 
los habitantes, nuevas políticas públicas y nuevos equipamientos. Así, hoy se habla de gobernanza de riesgo de desastre, que entre otras cosas busca activar redes de comunicación y trabajo entre gobiernos, academia, organizaciones de la sociedad civil y la empresa privada. Estos ejercicios, por cierto, raramente consideran saberes y procedimientos que provengan desde el territorio y comunidades, y más bien operan bajo una lógica tecno-administrativa de tipo top-down. Esto implica que las comunidades en riesgo participan casi exclusivamente bajo la lógica de ser beneficiarios o de víctimas, y no como actores relevantes en la toma de decisiones (FSP, 2016b; 2016c; 2016d). Con ello, se obvian activos que sí existen en los pueblos indígenas (Lauer, 2012; Srivastava, 2012) y rurales (Olivares, 2012) a la vez de orden colectivo (FSP, 2016d) y que han sido incorporados en base a una experiencia previa que es capitalizada como conocimiento y práctica (García, 2009), tal como se evidencia en el caso del propio pueblo Mapuche-lafkenche ante el terremoto del 27 de Febrero de 2010 -Chile- y la evacuación total de la comunidad costera de Tirúa, acción basada en su conocimiento ancestral por sobre la estructura estatal de riesgo de desastres (Cadierno, 2016). Más aún, hoy en día se exige internacionalmente que ello ocurra (Marco de Sendai 2015-2013, objetivos 15 y 23, ver en UNISDR, 2015).

Las biografías de estos siniestros con frecuencia parten desde la manifestación del mismo. Por ejemplo: un gran temporal, excepcionalmente lluvioso, desencadena la inestabilidad de un cerro altamente poblado, el que se desliza provocando la destrucción de viviendas, equipamiento público y, por sobre todo, muertes. Pero es menos común que la biografía de este evento retroceda y se pregunte ¿por qué esas familias se aglomeraron en un cerro que podía, potencialmente, venirse abajo?. Muchas veces esto se debe a desplazamientos humanos no intencionados, recientes o muy antiguos, demostrando un fenómeno de segregación o expulsión desde territorios más seguros, causada por intereses privados, violencia, expansión urbana, etc. Estos desplazamientos precarizantes ocurrieron bajo el alero de decisiones normadas, validadas por el Estado, actuando como un mecanismo de presión que genera pobreza, la que se sitúa en lugares altamente vulnerables (Blaikie et al., 1996). Tal es el caso de innumerables tragedias socioambientales que han ocurrido en Chile, y muy especialmente en territorios indígenas, fenómeno que sigue vigente con nuevas intervenciones normadas (obras viales que alteran la morfología y dinámica local, hidroeléctricas, industrias extractivas con altas externalidades negativas, etc.) que alteran a sus habitantes y desencadenan nuevas dinámicas precarizantes (Aylwin, 2000).

Lo más complejo del problema es que cuando estas familias, altamente expuestas a amenazas y riesgos ambientales, se enfrentan a un siniestro de estas características, su capacidad para reaccionar -y luego buscar un modo de restaurar su habitar previo- se encuentra seriamente debilitado, incluso enajenado. No es lo mismo asumir un siniestro ambiental como una comunidad empoderada, arraigada a un territorio propio y con un tejido social poblado de recursos activos, y donde su medio de vida se encuentra balanceado con su uso (FAO, 2016), que una comunidad desarraigada y debilitada, llena de pasivos e inmovilizada por barreras, con un medio de vida degradado, dependiente de la asistencia social pues su estado es tal que sin ésta le es imposible sostenerse ya que se encuentran en situación de pobreza crónica. Pero, paradójicamente, su precariedad es responsabilizada a ellos mismos. Es más, es usada como causal de desastres, reiterando la afirmación de que son los pobres quienes debilitan a la naturaleza (por ejemplo, cuando talan las laderas de un cerro para extraer leña, omitiendo con ello que hacen esto bajo una situación de estrés extremo). Por el contrario, el capital social de estas comunidades es fundamental, pues les otorga control de la situación, resistencia (Aguirre, 2004) y la posibilidad de asegurar mínimos ambientales.

\section{LA EXPERIENCIA DE LEWFU BUDI Y LA RESTAURACIÓN DE UN MAYOR GRADO DE AUTONOMÍA}

Durante la década de 1990, las familias asociadas a la localidad de Llaguepulli (costa sureste del lago Budi, comuna de Teodoro Schmidth), hicieron patente su interés por aprovechar los recursos paisajísticos, culturales y de biodiversidad que poseía su territorio (ver Tabla 1), creando un pequeño camping que, en el año 2000 , dio paso a una pequeña ruka para comercializar productos alimenticios.

Era una época compleja pues muchas familias de este territorio Mapuche-lafkenche veían con desaliento cómo obras viales avanzaban sobre la zona, las que eran asociadas en el imaginario y experiencia a la expansión de la industria forestal y de otros privados, por lo que se consideraba 
una amenaza, aparejada también con un latente, pero importante, éxodo de jóvenes. En paralelo, la naciente Ley de Pesca y Acuicultura ponía en riesgo la actividad litoraleña de estas comunidades pues otorgaba acceso exclusivo a sindicatos de pescadores artesanales (a través de figuras administrativas como las áreas de manejo de recursos bentónicos, amerb), y no consideraba los arreglos tradicionales sobre el entorno marino costero, tanto productivos como cosmogónicos y festivos (uso consuetudinario) Las escasas intervenciones formales desde el Estado hacia que estas familias se sustentaban en el asistencialismo, aunque la reciente promulgación de la Ley Indígena N019.253 generaba esperanzas para modificar este patrón.

Es por ello que esta iniciativa turística, en este escenario, era un intento por abrir una ventana ante un futuro principalmente incierto, en una historia que de por sí había sido largamente incierta y precarizante. Por lo mismo, muchos desconfiaban de esto:

"No sabíamos qué significaba el concepto de turismo. Era un concepto súper occidental, súper técnico, que jamás los mapuches lo manejamos, [...] y algunos me dijeron: -'chuta Mauricio, nosotros no sabemos qué significa el turismo, ¿qué será turismo?, ¿será que con el turismo van a llegar huincas?' - me dijeron así, con esos términos -'gente gringa' [...] ¿y no será que con el turismo vamos a ser invadidos nuevamente como nos han invadido, nos han quitado las tierras?, ¿y hoy en día tenemos tan pocas tierras?, ¿y producto de eso tenemos la pobreza hoy en día?, ¿será que va a ser bueno si hacemos turismo, si nos abrimos al turismo?".

Ex-Presidente de la agrupación de emprendedores turísticos de LLaguepulli. Documental Küme mogen lewfü Budi (Larraín, 2017)

Es necesario, además, contextualizar que esta iniciativa se originó en un momento en el que ong's como Fundación Impulsa, Fundación Nacional para la Superación de la Pobreza, y servicios públicos como CONADI $^{4}$ y FOSIS ${ }^{5}$, estaban comenzando un proceso de intervención focalizada en estas comunidades que buscaba reconocer la singularidad con que estas familias percibían y valoraban este espacio. Ello no es menor, si se considera que sustentaban su tejido social en la adscripción a Lof, los que coexistían con los sistemas políticos administrativos desplegados por el Estado que habían fragmentado espacialmente su territorio lacustre y costero. Y allí residía uno de los problemas importantes para comprender a esta zona, pues el Estado insistía en abordarlos sin considerar su cultura:

La forma "[...] como uno define los territorios dista mucho de cómo las comunidades indígenas visualizan el espacio territorial, que no tiene que ver con el límite que yo acuerdo contigo respecto de mi propiedad, sino que tiene que ver con una espacialidad muy distinta [...] el lago Budi para ellos era todo lo que ocurría allí, en la tierra, en el lago, era todo lo que había allí. Porque ellos visualizan el agua pero también entienden que hay una inmaterialidad en el agua, que es el Ngen-ko, que es el protector del agua y el protector de los recursos que hay ahí también. Y esa es una visión que uno no logra tener sino hasta que te metes a conversar con ellos desde el lago, y desde el lago ves el resto del territorio".

\section{Ex-profesional Servicio País Budi. Documental Küme mogen lewfü Budi (Larraín, 2017)}

Gracias a este proceso de interacción entre las organizaciones Mapuche-lafkenches y esta estructura de oportunidades (que involucra, por supuesto, muchos más hitos, ver Tabla 1) la comunidad de Llaguepulli fue reconocida en el registro de CONADI a mediados de dicha década, y en 1997 lograron la figura de Área de Desarrollo Indígena del lago Budi (ADI Budi), lo que permitió reforzar los esfuerzos y recursos hacia estas comunidades (Montero, 2014).

Frente a esta incipiente idea, algunos servicios del Estado se involucraron, lo que permitió que se creara una plataforma común de trabajo ${ }^{6}$. Esto significó acercar la estructura de oportunidades público-privada a esta zona y poner a disposición financiamiento y equipos de trabajo para ello, los que se sumaron a las ong's y actores locales que estaban acompañando a estas comunidades. Este ejercicio ocurrió velozmente (Rimisp, 2013) durante esta segunda década (2000 en adelante), surgiendo la primera cabaña y ruka turística el año 2002 en la zona de Llaguepulli, a la que pronto 
se sumaron otras, como se aprecia en la Figura 3. Se trata, por cierto, de estructuras monumentales y que guardan relación con una arquitectura propia de larga data que logró ser mantenida en su esencia. El 2003 se incorporó -como actividad complementaria- el relato de historias contadas en la ruka por kimches, hombres sabios, como se observa en la Figura 4. En esta imagen aparece un grupo de visitantes escuchando relatos propios de la comunidad de Llaguepulli por parte de sus integrantes.

\begin{tabular}{ll} 
Año & Acontecimiento \\
\hline 1993 & Se aprueba la Ley indígena 19.253 \\
\hline 1995 & - La situación de pobreza y despoblamiento se vuelve extrema en el Budi. El aislamiento, \\
& las actividades productivas tradicionales (recolección de orilla, agrícola/ganadera) y la \\
& capacidad ecológica del territorio, hacen muy difícil sostener siquiera una economía de \\
& subsistencia y generar ingresos por sobre la línea de la pobreza de la época. Se vuelve \\
& prácticamente imposible desplegar una estrategia de desarrollo local bajo dichos \\
& parámetros y retener a la población en el territorio \\
& El 12 de junio de 1995 se crea la Comunidad indígena Llaguepulli, sector rural \\
& de la comuna de Teodoro Schmidt, inscrita en el registro de comunidades y \\
& asociaciones indígenas de la CONADI, Subdirección Nacional Temuco, bajo en \\
& N0725. RUT: $53.229 .960-8$
\end{tabular}

Tabla 1. Línea de tiempo década 1990: Cuadro sintético con los hitos más importantes de esta historia Fuente: Autor, 2019

Durante el 2004 se sumaron actividades tradicionales a esta iniciativa (principalmente agropecuarias y de recreación). Y debido a que la demanda aumentó en esos primeros dos años, la idea se expandió el año 2005, sumando a 17 familias locales y apalancando recursos para contar con embarcaciones y acceder a los recursos naturales del lago, conformando el Comité de turismo Mapuche-lafkenche. Algo notable en este aspecto fue la reactivación de fabricación y navegación con bongos, también llamados wampos (canoas monóxilas).

Esta organización permitió ampliar la oferta de actividades culturales a las que podían acceder los turistas, pero manteniendo en reserva actividades que eran íntimas y propias de los miembros de la comunidad, por sobre todo de carácter religioso:

"Fue un tema un poquito complicado al principio, porque había gente que estaba a favor, y mucha gente que estaba en contra del turismo, porque ellos creían que por medio del turismo íbamos a folklorizar la cultura o íbamos a vender la cultura, o se iba a perder esa conexión que nosotros tenemos con las ceremonias principalmente. Entonces, las familias

7. Celebración del año nuevo mapuche basado en el solsticio de invierno

8. Importante ceremonia religiosa mapuche que vincula con el mundo espiritual. 
que quisieron emprender dijeron: -'cierta parte de la cultura vamos a poner a disposición del turismo, pero las cosas más sagradas nuestras van a quedar completamente a un lado".

Administradora Centro Cultural y Gastronómico Kom Che Ñi Ruka. Documental Küme mogen lewfü Budi (Larraín, 2017)

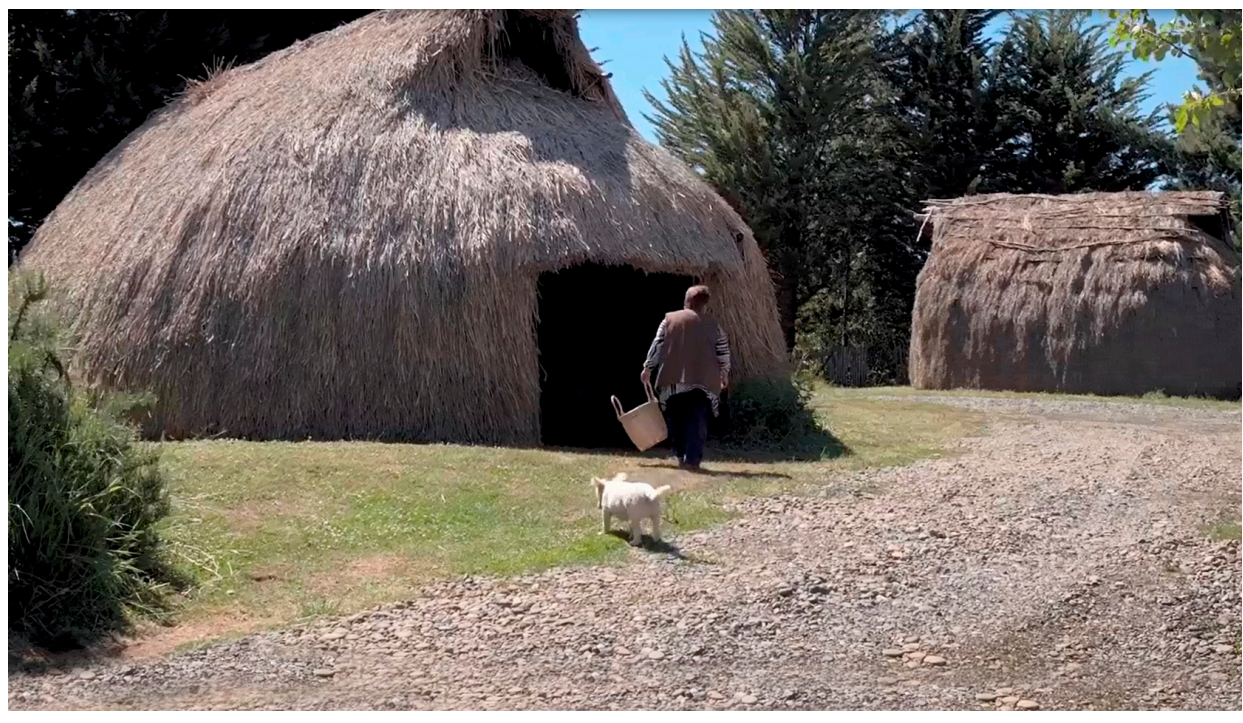

Figura 3. Rukas turísticas en Llaguepulli

Fuente: Documental Küme mogen lewfü Budi (Larraín, 2017).



Figura 4. Relatos contados a turistas dentro de la Ruka Fuente: Documental Küme mogen lewfü Budi (Larraín, 2017).

El año 2006 lograron romper con el temor a formalizarse, inseguridad que tenía múltiples razones históricas y que estaba poniendo en riesgo esta iniciativa: "Las primeras gestiones implicaron multas del servicio de impuestos internos, deudas" -Pablo Calfuqueo, Tour operador de Llaguepulli. Documental Küme mogen lewfü Budi (Larraín, 2017). También se resolvieron carencias históricas, como contar con agua potabilizada, elemento que es excluyente si se quiere iniciar una actividad comercial en cualquier parte del país. A su vez, esta estructuración organizacional implicó la asignación de roles específicos entre sus miembros, y la creación de un centro cultural y gastronómico llamado Kom Che Ñi Ruka, lo que permitió contratar a miembros de la comunidad como asalariados.

Todos estos pasos permiten advertir que lograron establecer una modalidad dual de aprovechamiento del territorio: por un lado, sus espacios de vida seguían manteniendo una lógica tradicional basada en cuatro principios: Küme Mogen-Buen Vivir; Keyuwun-Trabajo Mancomunado; Itxofill Mogen-Responsabilidad Ambiental y Cultural; y Rüf Zugu-Honestidad; así como autoridades tradicionales y modos de habitar propios (regulaciones consuetudinarias), las que incluían 
pequeñas ventanas para el acceso controlado de visitantes externos (paseos en carreta, relatos, culinaria, etc.). Y por otro, aprovecharon la estructura de oportunidades público-privada recreando las formas y exigencias que el propio Estado imponía.

Esto es fundamental, pues en lugar de reemplazar un modelo de vida, problema usual que afecta a los habitantes de territorios aislados, rurales o isleños que desean acceder a estas oportunidades, en este caso estas comunidades decidieron mantener dos modalidades de organización y toma de decisiones, lo que les permitió un mayor control territorial y sobre su futuro. Basalmente, el piso o soporte que les ayudó a sortear la prolongada historia de siniestros e invisibilidad fue, por sobre todo, el tejido social, simbólico y de gobernanza tradicional basado en el Lof. Es también este sustrato el que les permite hoy en día reaccionar de forma más organizada y segura frente a la posibilidad de siniestros, sean socioambientales o normativos, como está ocurriendo con las sequías asociadas al cambio climático, o está latente cada vez que arriba a la zona una nueva oportunidad basada en la competencia individual, sea a través de la manifestación de carencias (como cuando se accede a un bono o subsidio) o buscando lucro (negocios):

"La idea es que, de alguna manera, todos vayan teniendo clientes a través de esta modalidad. A través de un encadenamiento de la prestación de servicios. Y como estamos con un espíritu de trabajar mancomunadamente aquí no funciona la libre competencia [...] así como decir: 'ya, yo voy por la mía, y ya está'. O sea, en el fondo los que más saben tienen que ayudar al otro para que el otro también salga adelante. Ese es el propósito. Es un tipo de negocio diferente".

Tour operador de Llaguepulli. Documental Küme mogen lewfü Budi (Larraín, 2017)

Un ejemplo reciente del control que está teniendo este grupo de comunidades es lo ocurrido con subsidios del Ministerio de la Vivienda (MINVU): en lugar de recrear la estandarizada vivienda social común a todo el país, modificaron su diseño aproximándose la idea de una ruka. Lo mismo sucedió con la creación de un sistema de crédito interno, que no obedece a las reglas del mercado (como sí sucede cuando asisten a la banca o a préstamos estatales) y que, al contrario, busca proteger a las familias; o el giro que han realizado -por ejemplo- respecto de intervenciones de apoyo agropecuarias por parte del Estado, haciendo que en lugar de introducir especies exógenas se revitalice la biodiversidad hortícola Mapuche-lafkenche a partir de bancos de semillas comunitarios; o con la escuela Kom Pu Lof Ñi Kimeltuwe, que administra la propia comunidad a través de la Sociedad Educacional Kimeltuchefe Ltda. (Figura 5):

"Empezamos a averiguar cómo nuestros antepasados ellos hacían economía. 0 qué significaba economía para ellos. Entonces ahí llegamos al resultado de que la economía para ellos era el txafkintu, el intercambio. De esa forma ellos hacían economía. No estaba de por medio el dinero. Entonces dijimos 'ya, vamos a crear una cooperativa de ahorro y crédito'. Entonces, el primer año se atrevieron doce personas. Hoy día, entre socios internos y socios externos, tenemos cuarenta. ¡Ahí si somos completamente autónomos!, porque ahí no estamos intervenidos por nada. Entonces, por ejemplo, nosotros estamos bajo el alero de la comunidad, la comunidad tiene personalidad jurídica y cuando nosotros queremos postular a un proyecto -como apoyo mutuo- lo postula la comunidad [...] Y también creamos un banco de semillas. Llegó PRODESAL ${ }^{9}$, el PDTI ${ }^{10}$, que están bajo el alero de INDAP. Entonces, en un tiempo, ellos entregaban muchas de esas cosas, como semillas transgénicas y todo ese tema. Entonces, igual hoy en día con ellos hemos tratado de cambiar el chip y decirles 'mira, nosotros como comunidad estamos en otra onda y nosotros vamos por ese lado y no por el lado que van ustede'. Entonces, de alguna forma, ellos se han ido acomodando al lado que vamos nosotros [...] Ya llevamos dos años enfocados a eso. Entonces, ¿qué es lo que hemos logrado con eso?: tener nuestra propia alimentación, una alimentación más sana, incorporar semillas que antes habían acá y que se habían perdido, recuperar las semillas. Y hoy en día Llaguepulli es un referente en distintos ámbitos: primero, un referente en el ámbito del turismo, pero también hoy en día somos referente a nivel nacional en el ámbito educativo porque somos la primera comunidad, la única comunidad indígena de Chile, que administra su propio colegio". 


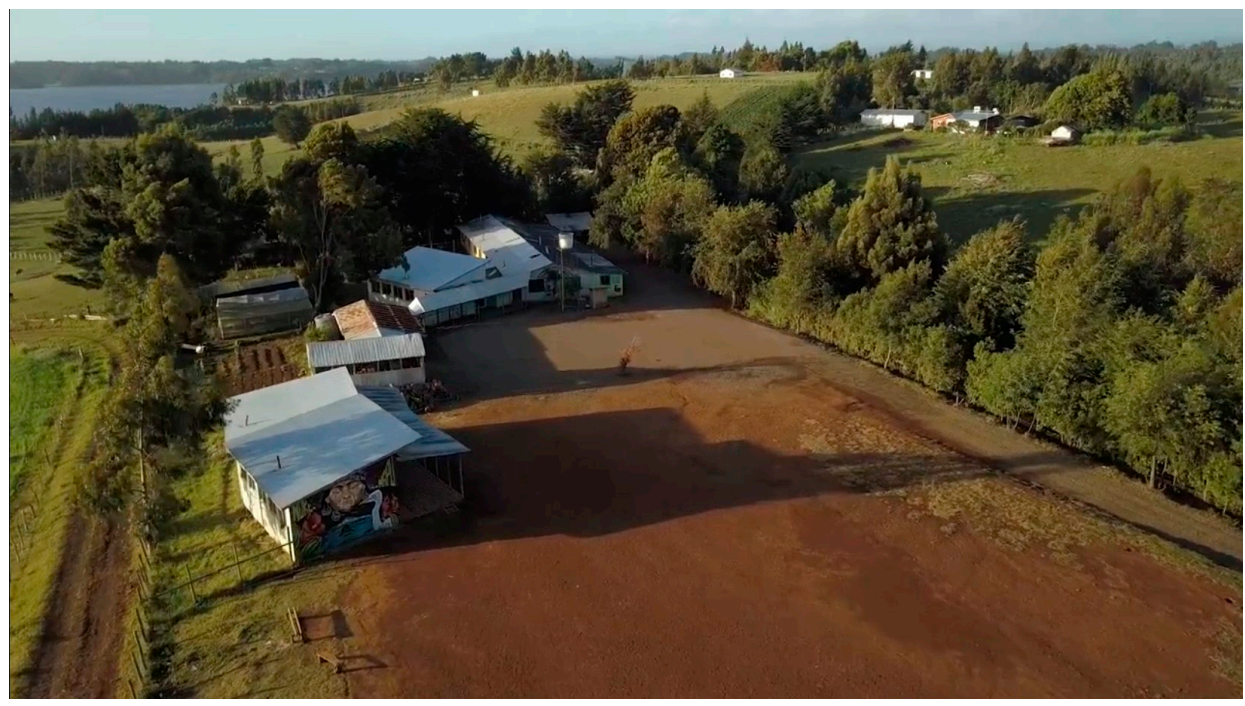

Figura 5. Escuela Kom Pu Lof Ñi Kimeltuwe

Fuente: Documental Küme mogen lewfü Budi (Larraín, 2017)

Este hito es especialmente significativo por el impacto que tiene hoy en día y a futuro:

"El magisterio nunca imaginó que la comunidad iba a tener tal nivel de apropiación de este territorio, que iba a demandar la recuperación de su escuela [...] y esto hace que las familias, los niños y niñas, tengan formación pertinente a su cultura, y que además esa formación vaya a impactar directamente en la sustentabilidad del trabajo que ellos hoy día realizan, este turismo rural-cultural va a quedar transmitido a toda esta nueva generación que se está formando en esta escuela de Llaguepulli".

Gaby Marihuán, Directora Regional Fundación Superación Pobreza Araucanía

Finalmente, todas estas estas transformaciones (Tabla 2) también incluyen las formas de visibilización ante la región y el país (y también el mundo), pues a partir del ejercicio turístico formalizado elaboraron una página web para promocionar su propuesta de desarrollo local ${ }^{11}$, lo que ha facilitado el arribo de más visitantes.

\begin{tabular}{ll} 
Año & Acontecimiento \\
\hline 2002 & $\begin{array}{l}\text { - Con ONG Impulsa que realizan capacitaciones en marketing, contabilidad, atención de } \\
\text { público, etc. } \\
\text { - Con apoyo de CONADI se construye la primera ruka destinada al hospedaje }\end{array}$ \\
\hline 2003 & - Ese mismo verano camping recibe 400 personas aprox. \\
& - Se diversifican los servicios turísticos: exhibición de juegos de palin, paseos en carretas \\
& y cabalgatas
\end{tabular}

2005 - El 16 de septiembre de 2005, con apoyo de la Municipalidad de Teodoro Schmidt, 17 familias de Llaguepulli conforman agrupación funcional bajo la figura de Comité de Turismo mapuche-lafkenche. Certificado $\mathrm{N}^{\circ} 252$, I municipalidad Libro 7 folio 01 . RUT: $65,589,440-3$

- FOSIS entrega recursos para adquisición de botes con equipamiento para avistamiento de aves

- Se implementan talleres de tejido y artesanía

- Se incluyen aspectos musicales y danza

- Se construye un huerto medicinal y se venden productos envasados

- Llaguepulli comienza a transferir su experiencia y capacitar a otras comunidades 


\begin{tabular}{|c|c|}
\hline Año & Acontecimiento \\
\hline 2006 & $\begin{array}{l}\text { - Se inicia la formalización comercial y tributaria de la iniciativa, obtención de resolución } \\
\text { sanitaria } \\
\text { - Se crea el Centro cultural y gastronómico Kom Che Ñi Ruka, la casa de todos. Se crean } \\
10 \text { puestos de trabajo } \\
\text { - Se traspasa la escuela Rayenco a cargo del Magisterio a la comunidad de } \\
\text { Llaguepulli con el apoyo del Consejo Pü Werken lof Budi que agrupa a las } 119 \\
\text { comunidades del ADI Budi. Se crea el Consejo de Educación de la comuni- } \\
\text { dad, SOCIEDAD EDUCACIONAL KIMELTUCHEFE LIMITADA, Rut 77350640-K, } \\
\text { compuesto por autoridades tradicionales, alumnos, profesores, administra- } \\
\text { tivos. Única escuela autónoma administrada por organizaciones tradicional. } \\
\text { Finalmente, de Rayenco la escuela pasa a llamarse Kom pu lof Ñi Kimeltuwe. En } \\
2003 \text { tenía } 10 \text { alumnos y un profesor. Ahora cuenta con } 80 \text { alumnos y } 15 \text { traba- } \\
\text { jadores. Dos furgones trasladan a los alumnos }\end{array}$ \\
\hline 2007 & $\begin{array}{l}\text { - El comité de turismo a esta fecha cuenta con } 80 \text { camas en rukas y cabañas, } 6 \text { botes, } 5 \\
\text { kayaks, } 10 \text { caballos para cabalgatas } \\
\text { - Apoyo de la comunidad a jóvenes de la comunidad para estudiar turismo y temas } \\
\text { asociados en educación secundaria y superior }\end{array}$ \\
\hline 2008 & - Egresan los primeros 4 niños de 8vo básico de la escuela Kom pü lof \\
\hline 2013 & $\begin{array}{l}\text { - Con la ayuda de ONG MAPLE, surge el Grupo Apoyo Mutuo en la Comunidad de } \\
\text { Llaguepulli: Rekvlvwun Keyuwun. Su misión es implementar un sistema de economía } \\
\text { justa, solidaria, y autónoma, basado en la confianza, reciprocidad y en valores cultu- } \\
\text { rales propios ancestrales mapuche-lafkenche, implementando auto-gestión y una } \\
\text { actitud proactiva hacia la solución de los requerimientos económicos de la organización. } \\
\text { Mediante apoyo económico, técnico y colaborativo, impulsa proyectos de las familias de } \\
\text { la comunidad en distintas áreas }\end{array}$ \\
\hline 2014 & $\begin{array}{l}\text { - Con el apoyo de la ONG Semillas del Cambio, surge el banco de semillas que recupera } \\
\text { cultivos orgánicos y tradicionales. Estos dieron origen a las Canastas de Apoyo Mutuo } \\
\text { que traen alimentos sanos y nutritivos, cultivados por mapuche-lafkenche de la } \\
\text { manera tradicional, aportando así a las economías familiares tanto como a la salud de } \\
\text { quienes disfrutan de éstos }\end{array}$ \\
\hline
\end{tabular}

Tabla 2. Línea de tiempo década. Cuadro sintético con los hitos más importantes de esta historia Fuente: Autor, 2019

\section{CONCLUSIONES}

La experiencia de lago Budi presenta múltiples lecturas. Su relevancia radica en ser una experiencia colectiva, solidaria, basada en cuatro principios: Küme Mogen-Buen Vivir; Keyuwun-Trabajo Mancomunado; Itxofill Mogen-Responsabilidad Ambiental y Cultural; y Rüf Zugu-Honestidad, aunque la lectura de ésta iniciativa por parte de la sociedad nacional siga siendo parcial, como cuando se toman en cuenta aspectos que más bien forman parte del modelo de desarrollo imperante: esto sucede cuando sólo se destaca la iniciativa como competitiva en el mercado (asumiendo que con ello se asegura su sustentabilidad comercial). Esto se aleja notablemente del sentido original propuesto por estas comunidades, tal como señala en el relato previo Pablo Calfuqueo.

La superación de la pobreza implica analizar transformaciones que van mucho más allá del aumento de tenencias e ingresos. La contracara de la pobreza no es sólo un aumento de circunstancias en la dotación de bienes y servicios, sino que implica abrazar el desarrollo local y social como horizonte. En dicha construcción juegan un papel trascendental los cambios subjetivos, objetivos y relacionales experimentados por la comunidad (ver Tabla 3).

Si revisamos el proceso vivido por la comunidad de Llaguepulli podemos advertir cambios muy relevantes en todos y cada uno estos aspectos:

Cambios objetivos: Las familias involucradas logran mayores recursos económicos; consiguieron administrar su escuela; crearon una Cooperativa de apoyo mutuo; un banco de semillas; infraestructura turística que permite alojar y alimentar visitantes, o facilitar el disfrute de los recursos naturales locales (por ejemplo, con bongos o embarcaciones diversas, etc. 


\begin{tabular}{|c|c|c|}
\hline Cambios subjetivos & Cambios objetivos & Cambios relacionales \\
\hline $\begin{array}{l}\text { Hace referencia a transforma- } \\
\text { ciones positivas en el ámbito de } \\
\text { la interioridad de un sujeto. Se } \\
\text { trata de modificaciones variadas } \\
\text { y muy importantes como el } \\
\text { auto-concepto, la autoestima, } \\
\text { la auto-representación social, } \\
\text { las configuraciones mentales y } \\
\text { reflexivas, los valores, creencias, } \\
\text { las emociones y sentimientos. } \\
\text { Estos suelen ser un reflejo de la } \\
\text { interacción de las personas con su } \\
\text { propia interioridad, como también } \\
\text { con los elementos que le rodean. } \\
\text { Los cambios subjetivos tienden a } \\
\text { manifestarse en relatos y testi- } \\
\text { monios sentidos y significativos } \\
\text { de transformación personal. }\end{array}$ & $\begin{array}{l}\text { Hace referencia a las trans- } \\
\text { formaciones positivas en el } \\
\text { ámbito de la exterioridad de un } \\
\text { individuo. Suelen tener existen- } \\
\text { cia inter-subjetiva. Se trata de } \\
\text { modificaciones que pueden ser } \\
\text { reducidas a hechos. Si bien los } \\
\text { cambios objetivos comúnmente } \\
\text { se asocian a transformaciones } \\
\text { tangibles o materiales, también } \\
\text { pueden incluir comportamien- } \\
\text { tos, conductas, etc. Los cambios } \\
\text { objetivos, en su mayoría, se } \\
\text { manifiestan de manera evidente } \\
\text { en alteraciones físicas o directa- } \\
\text { mente observables, es decir, que } \\
\text { no requieren a priori del relato o } \\
\text { testimonio de los individuos para } \\
\text { ser detectados por terceros. }\end{array}$ & $\begin{array}{l}\text { Pueden ser comprendidos como } \\
\text { un tipo de transformación obje- } \\
\text { tiva, en la medida que las rela- } \\
\text { ciones sociales suelen expresarse } \\
\text { en comportamientos y conductas } \\
\text { de interacción entre individuos, } \\
\text { sujetos, actores, etc. En el caso } \\
\text { de situaciones de pobreza, este } \\
\text { tipo de cambios guarda relación } \\
\text { con la retracción de relaciones } \\
\text { asimétricas, basadas en prácticas } \\
\text { de asistencia, dependencia, } \\
\text { subordinación, aislamiento, hu- } \\
\text { millación, infantilización, etc. }\end{array}$ \\
\hline
\end{tabular}

Tabla 3. Cambios subjetivos, objetivos y relacionales involucrados en esta historia Fuente: Autor, 2019

Cambios subjetivos: La comunidad pasó de tener un auto-concepto devaluado -de sentimientos de vergüenza y desesperanza- a un contexto de mayor reafirmación, orgullo y el optimismo de un futuro mejor, basados en el küme mogen, lo que implica reactivar una compleja arquitectura propia, muy sólida por cierto, que se mantuvo en latencia a microescala y que hoy en día se expande, otorga confianza y convoca.

Cambios relacionales: La comunidad pasó del aislamiento (causado por agentes externos, pero también internos a manera de protección), dependencia asistencial y subordinación; a una situación de nueva autonomía, autogestión y vínculo con decenas de instituciones diferentes, de manera empoderada, propositiva y deliberativa.

En esto jugó un papel muy relevante el portafolio de recursos de la propia comunidad (ver Tabla 4).

\begin{tabular}{|c|c|c|c|}
\hline Recursos humanos & Recursos sociales & Recursos culturales & Recursos naturales \\
\hline $\begin{array}{l}\text { Liderazgo; Capacidad de } \\
\text { aprender; El apego territo- } \\
\text { rial; La capacidad de trabajo; } \\
\text { La disposición al cambio; } \\
\text { Apego filial, etc. }\end{array}$ & $\begin{array}{l}\text { Redes vecinales y familiares; } \\
\text { Formas organizativas (uti- } \\
\text { lizadas como estrategias de } \\
\text { acceso a la E.O). tales como: } \\
\text { Comunidad indígena - para } \\
\text { interactuar con CONADI-, } \\
\text { Comité de turismo mapu- } \\
\text { che-lafkenche -para interac- } \\
\text { tuar con SERNATUR, FOSIS, } \\
\text { Municipalidad, etc., Sociedad } \\
\text { educativa - para interactuar } \\
\text { con MINEDUC-, etc. }\end{array}$ & $\begin{array}{l}\text { Identidad; Prácticas cul- } \\
\text { turales vivas; El idioma; } \\
\text { Conocimiento de la tierra; } \\
\text { Oficios; Espiritualidad; } \\
\text { Arreglos valóricos; Küme } \\
\text { mogen, Keyüwün, Itxofill } \\
\text { Mogen, Rüf Zugu, Txawün, etc. }\end{array}$ & $\begin{array}{l}\text { El paisaje; Servicios } \\
\text { Ambientales; Biodiversidad, } \\
\text { etc. }\end{array}$ \\
\hline
\end{tabular}

Tabla 4. Portafolio de recursos comunitario

Fuente: Autor, 2019

Lo que evidencia este conjunto de comunidades es, por una parte, la capacidad comunitaria y ancestral para liberar la presión ejercida por los distintos siniestros normativos en el territorio; y, por otra, la instalación de una plataforma de interacción con las reglas del Estado y el mercado que les permite acceder a la estructura de oportunidades público-privada, pero que internamente da paso a regulaciones propias, consuetudinarias, en donde se privilegia la solidaridad y la equidad. Este control es fundamental pues permite identificar un "[...] sujeto colectivo [que] hubiera podido tomar cualquier oportunidad" -Ex-profesional Servicio País Budi. Documental Küme mogen lewfü Budi (Larraín, 2017)-, pero que carecía de validez y reconocimiento frente a una historia previa de dependencia y asistencialismo, por sobre todo de invisibilidad: "Hace treinta años atrás, veinticinco años atrás, Llaguepulli era una comunidad invisibilizada dentro del territorio" -Administradora Centro Cultural y Gastronómico Kom Che Ñi Ruka. Documental Küme mogen lewfü Budi (Larraín, 2017). 
Hoy en día se observa un giro importante pero que no es nuevo, sino que estuvo 'contenido', inmovilizado, durante mucho tiempo, y que posee una raigambre muy antigua -previa a la enajenación histórica sufrida. Por lo mismo, esta recomposición no debe ser tomada a la ligera considerando sólo referentes histórico-recientes. Por el contrario, para comprenderla hay que remontarse a un modo de vida que posee una larga biografía, hasta un tiempo en que los mapuche se desenvolvían libremente. Allí radica su riqueza y solidez, y la capacidad para haberse sostenido por tanto tiempo mancillada. Esto por supuesto es valorado por las generaciones que experimentan en la actualidad esta situación: "hoy en día nos transformamos en una comunidad referente ante la opinión de la región de La Araucanía, referente ante las otras regiones, referente a nivel de país y nos transformamos en un referente a nivel internacional" -Ex-Presidente de la agrupación de emprendedores turísticos de LLaguepulli. Documental Küme mogen lewfü Budi (Larraín, 2017); "Hoy día las familias tienen claro que situación que no está resuelta ellos pueden buscar la solución [...] están convencidas de que el cambio pasa por ellas mismas" - Directora Regional Fundación Superación Pobreza Araucanía. Documental Küme mogen lewfü Budi (Larraín, 2017).

Las familias locales señalan que el turismo que escogieron ha sido una opción para complementar sus economías. Al mismo tiempo, les otorga mayor seguridad respecto a la incertidumbre prolongada que debieron experimentar, pues no sólo se trata de apalancar recursos, sino del reconocimiento que otorga que estos dividendos nazcan de sus propios paisajes, cultura y manifestaciones tanto materiales como inmateriales. Con ello se rompe también la extensa experiencia de devaluación y prejuicios que no los consideraban a la altura de los demás habitantes de la región y del país. Pero esto no significa que los problemas que los afectan se hayan terminado, pues a macro escala territorial, y como pueblo originario siguen siendo vulnerables ante futuras políticas de desarrollo que no sean compatibles con su propuesta de desarrollo local. Por ejemplo, si se expande la industria forestal dentro de sus límites, u obras viales de gran envergadura, o si surgen o se incrementan los prejuicios basados en la actual crisis regional que señala al pueblo mapuche como un problema de seguridad para el país, entre otras.

Al respecto, esta historia ha tenido problemas que son parte de la reflexibilidad interna a estas comunidades. No todos consideran que el turismo es una opción pues implica exponerse ante otros, no tener el control absoluto sobre cómo se usara el territorio o su cultura (considerando, por ejemplo, agencias de turismo masivo que potencialmente podrían evitar a estas familias para aumentar sus ganancias), o el temor a proyectos inmobiliarios posibles que, con un cambio normativo, pudiesen instalarse en la costa. Frente a ello es necesario señalar que todo es posible, y con ello volvemos a recurrir al concepto de siniestro normativo: buena parte de lo que ocurra o no ocurra dependerá de la legislación nacional, y la historia demuestra que muchas veces puede ser significativamente perjudicial, y otras permitir el resguardo y mayor seguridad, pero sin que definitivamente exista la posibilidad de predecir a ciencia cierta qué sucederá. Es por ello que estas comunidades, incluso con esta iniciativa de turismo particular, pueden proyectarse de forma certera en el futuro, por lo que deben estar constantemente atentas a los vaivenes del país, cambios de gobierno, etc., y mantener un vínculo relacional con parlamentarios y autoridades de su comuna, región y país (labor que se ejerce a partir de plataformas políticas indígenas, como Identidad Lafkenche), con el propósito de pre-visualizar a tiempo cambios inesperados. Y también, en este contexto, no es menor poner en juego riesgos futuros asociados al cambio climático, terremotos, etc. que podrían ponerlos en jaque nuevamente.

Finalmente, nos parece importante considerar una reflexión final que señala la importancia que sigue teniendo el territorio como base identitaria y de vida. Este elemento sigue siendo la matriz que ha sostenido a estas comunidades y más hoy en día cuando su proyecto turístico-indígena contiene en sí un discurso de buen vivir distinto al que se experimenta bajo el modelo de desarrollo imperante. Lo esencial está en el sustrato comunitario y consuetudinario como estrategia para la superación de la pobreza y vulnerabilidad, a la vez de ser una herramienta para la gestión de riesgo de desastres y de liberación de presiones de orden normativo, político y económico (Blaike et al., 1996): "Hoy por hoy, si no tenemos espacios, si no tenemos tierras, dejamos de ser mapuche. Por eso exigimos derechos: derecho a nuestro espacio, derecho a nuestras tierras, para así de esa manera tener una mayor relación con ella. Para que la lógica mapuche, para que el mogen mapuche, siga por otros miles y miles de años más" -Ex-Presidente de la agrupación de emprendedores turísticos de LLaguepulli. Documental Küme mogen lewfü Budi (Larraín, 2017). 


\section{REFERENCIAS}

Aguirre, B. (2004). Los desastres en Latinoamérica: vulnerabilidad y resistencia. Revista mexicana de sociología, 66(3), 485-510.

Aylwin, J. (2000). Los conflictos en el territorio mapuche: antecedentes y perspectivas. Revista perspectivas, 3(2), 277-300.

Bengoa, J. (200o). Historia del pueblo mapuche: siglo XIX y XX (Ed. 7). Santiago de Chile: LOM ediciones.

Bengoa, J. (2017). Mapuche, colonos y el Estado Nacional. Santiago de Chile: Editorial Catalonia.

Blaikie, P., Cannon, T., Davis, I. \& Wisner, B. (1996). Vulnerabilidad: el entorno social, político y económico de los desastres. Bogotá, Colombia: LA RED \& Tercer Mundo Editores.

Cadierno, J. (2016). Transmisión de conocimiento ancestral Lafkenche sobre terremotos y tsunamis y su implicancia en la reducción del riesgo de desastres. Tesis M.Sc. Heidelberg, Alemania: Universität Heidelberg.

Casanueva, F. (2002). Indios malos en tierras buenas: Visión y concepción del mapuche según las elites chilenas (Siglo XIX). En Boccara, G. (Ed.) Colonización, resistencia y mestizaje en las Américas, Siglos XVI-XX. Quito, Ecuador: Abya-Yala, 291-328.

Carvallo, J., Obermoller, H., \& Jacquin, E. (2018). Análisis y Valoración del Proyecto Turístico Mapuche de la comunidad Llaguepulli, Araucanía, Chile. Revista de Turismo, Patrimonio y Desarrollo, 4(8), 42-53.

Castro, P. (2005). Aproximación a la identidad lafkenche. Perifèria, Revista d'investigació i formació en Antropologia, 2(1), 70-100.

Cayuqueo, P. (2012a). Solo por ser indios y otras crónicas mapuches. Santiago de Chile: Editorial Catalonia.

Cayuqueo, P. (2012b). La voz de los Lonkos. Santiago de Chile: Editorial Catalonia.

Centro Latinoamericano para el Desarrollo Rural RIMISP. (2013). Iniciativa turística Llaguepulli, territorio del Budi, comuna de Teodoro Schmidt. Documento de trabajo.

Cifuentes, N. \& Garrido, M. (2017). Áreas de Desarrollo Indígena Caso de estudio de la comunidad lafkenche "Llaguepulli". Documento de trabajo ICSO, $N^{\circ} 42$ Serie Jóvenes investigadores.

Cutter, S., Boruff, B.W. \& Lynn, S. (2003). Social Vulnerability to environmental Hazards. Social Science Querterly, 84(2), 242-261. DOI: 10.1111/1540-6237.8402002

Escalona, M., Peña, F. \& Hiriarte, R. (2012). Oferta turística y perfil sociocultural de los empresarios turísticos del borde costero de La Araucanía, Chile. Estudios y perspectivas en turismo, 21(2), 306-321.

Espíldora, B. (1972). Algunos antecedentes hidrológicos de la sequía en Chile. En Acta del Seminario Regional sobre Hidrología de Sequías. Montevideo: Oficina de Ciencias de la Unesco para América Latina, $181-184$.

Espinoza, C. (2016). Ley del borde costero y cuestión étnica en chile: del discurso a la práctica política. Universum (Talca), 31(1), 123-139.

Flores, F. (2009). La Ley Lafkenche: Construcción de la Ley de Borde Costero para los Pueblos Originarios y Estrategias de Incidencia desde el Movimiento Indígena. Documento de trabajo para el Proyecto Fondecyt, (1085180).

Foerster, R., \& Lavanchy, J. (1999). La problemática mapuche. Análisis del año (2), 65-102.

Fundación Superación de la Pobreza FSP. (2016a). Sembrando crecimiento, cosechando injusticia. Un estudio de percepción sobre los efectos de la industria forestal y energética en comunidades rurales de la región del Biobío. Estudio Regional Biobío. Concepción: FSP.

Fundación Superación de la Pobreza FSP. (2016b). Jugando entre riesgos. Representaciones, sentimientos e imágenes de niños y niñas afectados por tres siniestros socioambientales en la región de Valparaíso. Estudio Regional Valparaíso. Valparaiso: FSP.

Fundación Superación de la Pobreza FSP. (2016c). Crisis en el habitar insular. Representaciones, significados y sentimientos de los habitantes del mar interior de Chiloé sobre la crisis sociocultural 
y productiva de la isla, sus dinámicas presentes e imágenes de futuro. Estudio regional Los Lagos. Puerto Montt: FSP.

Fundación Superación de la Pobreza FSP. (2016d). Más allá del barro. Un análisis de las estrategias desplegadas por las comunidades afectadas ante el $25 \mathrm{M}$ en Atacama. Estudio regional Atacama. Calama: FSP.

García, V. (2009). Prevención de desastres, estrategias adaptativas y capital social. En Koff, H. et al. (Eds.) Social Cohesion in Europe and the Americas: Power, Time and Space. Germany: PIE Peter Lang, 115-130.

Gissi, N., Ibacache, D., Pardo, B., \& Ñancucheo, M. (2018). El Estado chileno, los lafkenche y la Ley 20.249:¿ Indigenismo o política del reconocimiento? Revista Austral de Ciencias Sociales, (32), 5-21.

Herrera, R. (2003). La construcción histórica de La Araucanía: desde la historiografía oficial a las imágenes culturales y dominación política. Revista Austral de Ciencias Sociales, (7), 29-40.

Kaztman, R., \& Filgueira, C. (1999). Marco conceptual sobre activos, vulnerabilidad y estructura de oportunidades. Montevideo: PNUD \& CEPAL.

Laraín, S. [Director] (2017). Küme mogen lewfü Budi. Buen vivir en el lago Budi. [Documental: 37 min.], En base a Levantamiento de Aprendizajes Servicio País “Red de turismo rural Lago Budi” (19982001), Fundación Superación Pobreza.

Lauer, M. (2012). Oral traditions or situated practices? Understanding how indigenous communities respond to environmental disasters. Human Organization, 71(2), 176-187. DOI: 10.17730/ humo.71.2.jow0101277ww6084

Max-Neef, M., Elizalde, A. \& Hopenhayn, M. (1993). Desarrollo a escala humana, conceptos, aplicaciones y algunas reflexiones. Montevideo: Editorial Nordan-comunidad.

Montalba, R., Vera, L. \& Vielli, L. (2011). Historia ecológica de la degradación de los bosques y recursos naturales en La Araucanía Chilena. En Bernal, H., C. Sierra, M. Onaindia, \& T. González (Eds.) Bosques del Mundo, Cambio Climático y Amazonía. País Vasco, España: Cátedra Unesco-EHU de DesarrolloSostenible y Educación Ambiental.

Montecino, S. (2011). Mito, sacrificio y políticas de la diferencia: el terremoto del 60 en el lago Budi. Revista Anales, 7(1), 201-206.

Montero, A. (2014). Levantamiento de Aprendizajes Servicio País “Red de turismo rural Lago Budi” (19982001). Santiago de Chile: FSP.

Neira, C.M. (2009). Transición a la democracia, militancia y proyecto étnico. La fundación de la organización mapuche Consejo de Todas las Tierras (1978-199o), Estudios Sociológicos, 27(80), 595-618.

Olivares, B. (2013). Transición del monólogo científico a la pluralidad cultural: conectando países para el fortalecimiento del conocimiento climático local latinoamericano. Revista Nexos, 2(1), 32-45.

Programa de las naciones Unidas para el Desarrollo PNUD. (1996). Desarrollo Humano en Chile. Santiago de Chile: PNUD Chile.

Srivastava, S. (2012). Managing indigenous and scientific knowledge for resilience building: Case studies from disaster-prone regions of India. Journal of Advances in Management Research, 9(1), $45-63$.

Toledo, V. (2001). Esto también va haciendo autonomía: La estrategia territorial de las comunidades lafkenches de Tirúa. En Salinas García, J. \& Cubillos Romo, J. (Eds.) Programa Ciudadanía y Gestión Local: Espacios Locales y Desarrollo de la Ciudadanía. Santiago de Chile: FSP \& Centro de Análisis de Políticas Publicas de la Universidad de Chile, 157-196.

United Nations International Strategy for Disaster Reduction UNISDR. (2015). Sendai Framework for Disaster Risk Reduction 2015-2030. Sendai: UNISDR.

Zelada, S. \& Park, J. (2013). Análisis crítico de la Ley Lafkenche ( $\mathrm{N}^{\circ}$ 20.249): El complejo contexto ideológico, jurídico, administrativo y social que dificulta su aplicación. Universum (Talca), 28(1), 47-72. 